\title{
INTERSUBJECTIVE APPROACH TO PRE-TRANSLATION ANALYSIS OF ARCHITECTURAL CRITICISM: REACHING AFTER THE BALANCE
}

\author{
Svetlana Latysheva \\ Irkutsk National Research Technical University, Russia
}

\begin{abstract}
The study discusses a new approach to translation of architectural critical materials focusing on the stage of source texts analysis. Architecture synthesizes science, technology, art and social sphere resulting in the heterogeneity of translatological characteristics of texts representing architectural phenomena. They combine the parameters of institutional and personal discourse possessing the features of specialized texts, such as the predominance of cognitive information and a high degree of conventionality, and artistic texts with their emotional, aesthetic and axiological aspects. This functional ambivalence limits the use of traditional methods based on genre or stylistic analysis. This research is an attempt to develop a new approach to pre-translation analysis of architectural texts yielding adequate translation methods for architectural nominations and contributing to the retainment of original text identity. The study views intersubjectivity in pre-translation analysis as conceptual coordination within the discourse of the expert community carried out in the process of interaction between authors of source texts and addressees of translation texts through interlingual mediation. The developed method allows translators to reveal relevant cognitive and discursive parameters of nominations of architectural phenomena at various language levels. In addition, it reveals the translation dominants that assist both to preserve the sufficient level of translation text conventionality within the institutional discourse of architecture and to transfer personal meanings and values implied by source text authors within their personal discourse.
\end{abstract}

Key words: pre-translation analysis, intersubjective approach, architectural criticism, translation strategy

\section{INTRODUCTION}

Most translation theorists and practitioners recognise the importance of source text analysis, and they admit that any skilled translator should develop a professional competence of specific perception and understanding of source texts. This aspect of translators' profession discussed in a significant number of works leads to one basic idea shared by the majority of researchers and expressed in Robinson D. (2012: 208) "It probably goes without saying: the ability to analyze a source text linguistically, culturally, even philosophically or politically is of paramount importance to the translator." At the

Submitted December $27^{\text {th }}, 2020$, accepted for publication February $16^{\text {th }}, 2021$

Corresponding author: Svetlana Latysheva. Irkutsk National Research Technical University, Str. Lermontov, 83,

Irkutsk, Russia|E-mail: lasveta1@yandex.ru 
same time, the assessment of essential features at this relevant stage in translation process is quite ambiguous, and this causes terminological variations in its description: translation analysis of source text, pre-translation analysis of source text, translation interpretation of source text, hermeneutical approach to translation. More options arise when correlating this activity with the phases of translation process: a component of translation strategy, a method of formation of translation competences, a stage of preparations preceding translation or translation itself.

Alternative approaches to translator's cognitive activity in the process of his or her interaction with original texts result not only from the variability of translation models, but also from the fact that translation studies are interdisciplinary. Therefore, this activity overlaps with many scientific fields, such as pure linguistic analysis, comparative analysis, contrastive language studies, literary analysis, literature studies, cultural analysis, logical analysis, psychological studies, etc.

However, there is a common approach typical of all mentioned analyses: text fragmentation, its division into semantic and / or structural components. After that, various functions arise derived from relations established between components, such as layers of meaning built up by various text units (Komissarov 2018), communicative outcomes (Latyshev 2016), illocutionary acts of translation, intentions (Nord 1991), types of information (Alekseeva 2008), genre and stylistic characteristics (Brandes \& Provotorov 2011), registers (Ballard 1980). Then, scholars rank these categories according to their influence on translation process in order to distinguish predominating ones. Finally, they develop translatological classifications of texts based on dominant categories linked with translation operations. The list of these categories and their relations vary; consequently, it results in a variety of classifications. The principles of their functioning are if not common, but at least not opposed to each other (Ayupova 2014). On this basis, scholars generate a list of recommendations, a nomenclature of interlingual matches or an algorithm of translation specified by types of source texts, that is a kind of translation matrix.

When put into translation practice, this matrix influences the choice of a translation strategy that is a high-level plan to achieve translation goals. In accordance with this, most researchers differentiate between the two basic strategies determined by target and source languages' ideology and culture, i.e. domestication and foreignization strategies (Kemppanen, Jänis, \& Belikova 2012).

Within the domesticating strategy, translators prefer to create texts that are more in compliance with the target culture in terms of lexical collocations, language structures, ethnic features, social practices, and symbols (Yang 2010). Consequently, domestication employs translation techniques imitating various features of the target culture and neutralizing the characteristics of the source culture. They are semantic and functional techniques of translation, focused on transferring semantic and pragmatic components of the source text. For example, functional replacement is the method expressing source text concepts by language units of the target text that differ from the language forms of the source text. The method known as specification transfers source language units with general meanings by means of target language units with more specific meanings. The method of generalization expresses source language units with specific meanings by means of target language units with more general meanings. The translation technique called explication transfers language units of the source text by giving definitions to them in the target text, and the method of meaning differentiation conveys source language units following the rules of target language 
collocations and employing target language units with similar, but not corresponding meanings.

Applying the foreignization strategy, translators demonstrate the opposite approach, as their translation techniques preserve source text elements recognized as foreign to the target culture (Yang 2010). In this case, translation methods are form-dependent, as they transfer formal characteristics of the source text to the target language. For example, the technique known as original form preservation employs foreign source text signs in the target text. The methods of transcription and transliteration transfer formal characteristics of words of the source text expressed in sounds and letters, respectively, by means of alphabetic or other signs of the target text. The technique called loan translation occur when language units of the source text appear in the target text borrowed by literal, wordfor-word or root-for-root translation.

Despite the variety of approaches to the problem of pre-translation analysis, two major trends determine strategies and techniques of source text translation. The first tendency, conventionally called objectivist one, puts into focus impersonal characteristics of source texts, separating, as a rule, their linguistic and extralinguistic parameters, and emphasizing their typed properties based on language facts and attendant verifiable circumstances. This approach supports the idea that text content is invariant, so it is possible to establish the relations of equivalence between source text and target text, presupposing that their subject matter does not depend on individuals who deal with it. Therefore, it is independent from individualities of source text author and translator, as well as any other specific, not stereotyped text properties. In this case, studies focus on functional styles, as they prescribe parameters of text formation in the original language and form a translation matrix predicting transformations in the target text determining the features of a similar typed text in the translation language. The key to success for a translator in this case is to follow the pattern of functional style or genre and to select correspondences based on its rules (Oyali 2015).

The second approach, by contrast, is subjectivist, as, within this framework, pretranslation analysis considers an alternative determining factor primarily influencing translation techniques. It is individual text design based on specific characteristics of its formal and semantic components described in terms of a subjective position of its author, his or her personal meanings and individuality. These characteristics regulate the ways and methods of translation, since the predominant purpose in this case is to preserve and / or to compensate in the target text all the individuality of the source text. Accordingly, all translation actions become heuristic rather than rule-based, so translators construct texts, but not reconstruct them (Gennaro 2011).

It is essential that both trends are traditionally associated with different fields of translation: the objectivist approach has more effectiveness when applied to technical translation, and the subjectivist approach is more in demand for the purposes of literary translation. These approaches also differentiate the roles of translators, who just perform algorithms having no impact on target text, in the first case, or who generates individual product creating translation text, in the second case.

In the case of architectural criticism as a source text, both subjective and objective approaches to pre-translation analysis appear problematic because such texts convey interpretative process of assessment aimed at diverse practices of architecture; therefore, they combine both individual and stereotyped parameters (Raman and Coyne 2000) that would form mutually exclusive tactics of translation within the framework of subjectivist 
and objectivist approaches. Consequently, the pre-translation analysis of source text in this case requires additional integrating methods provided by discourse-cognitive paradigm and intersubjective approach.

\section{RESEARCH METHODOLOGY}

The research is a case study of pre-translation analysis performed by the students of Architectural Department of Irkutsk National Research Technical University that was a part of their specialised translation course project. The source text was a book entitled 'The Architecture of Community' written by Leon Krier in 2009 in English. The author is known as one the most provocative architects and urban theoreticians in the world whose core audience includes architects, city planners, and academics. In this book, he confers with them about his thinking on how to make sustainable, humane, and attractive villages, towns, and cities. The text has distinction as the author's strong personality and academic authority create a system of original ideas expressed by means of extraordinary nominations that can be viewed both as terms and metaphors occurring in the context of technical descriptions.

The research was conducted according to the following procedure: 1) establishing the theoretical framework of the research, 2) collecting empirical data in the process of pretranslation analysis of the source text, 3) analyzing the data collected, 4) developing translation strategy and presenting the findings.

\section{THEORETICAL BACKGROUNDS}

In the broadest sense, pre-translation analysis provides an understanding of the original text. At the same time, the objectivist and subjectivist tendencies treat the process of source text understanding differently, i.e. as analysis (extraction of meanings) and synthesis (creative thinking, construction of meanings), respectively (Zlateva 2000). The specificity of architectural texts is the result of integration of these two trends. To understand architectural critics, a translator should act not only in the context of algorithms and interlingual matches, but to be a source of creation, a subject of cognition, a researcher, an author, synthesizing the results of scientific and aesthetic understanding of the world.

Traditional methods of pre-translation analysis involve correspondences belonging to various language levels. These approaches inevitably lead to an endless fragmentation of original texts, as described below: during the process of understanding the source text, the translator firstly identifies the meanings of words and their relationships starting from the sentence level, then in paragraphs and selected segments of the text and finally throughout the entire text (Seresová \& Breveníková 2019). Analytical approaches contradict the essential qualitative characteristics of texts that are coherence and integrity. This is particularly challenging in written domain-based translation, which reveals individual and social responsibilities of translators, and where the time of interaction with texts is less limited. The effectiveness of translators' cognitive interaction with structured knowledge represented in scientific texts, and the ability to correlate these structures with the conceptual apparatus of a particular branch of science or domain, comes to the fore.

As noted in (Alekseeva 2010), when translating a scientific text, a translator generates knowledge structures, so his or her efforts are not exclusively dependent on translation of 
a separate term viewed as a particle of information. Working with specialized texts, translators create a potentially dynamic intertextual space. In this sense, the methodology of scientific text translation becomes macro-centric. Accordingly, any scientific text is a part of the matrix of scientific knowledge accumulated by a given period of time (regressive intertextuality) and the basis for the further development of a certain field of knowledge (progressive intertextuality). These characteristics contribute to the didactic potential of specialized text translation (Latysheva \& Shchurik 2015), as all implied knowledge that is not articulated in the source text becomes evident through the text continuum of a specific domain.

Intertextuality, described in most studies as a stylistic device that increases the effectiveness of communication, represents communicative interaction in the framework of the theory of discourse, c.f.: texts that draw upon incorporate and decontextualized dialogues with other texts (Paiva 1969). Engaging discourse and cognitive paradigms as a complex tool of analysis allows translators to examine the links between cognition and human factor and study similarities and differences across cultures (Qassem \& Gurindapalli 2019).

Text communicative interaction correlates with the idea of internal dialogism or polyphony discussed in (Bakhtin 2010). This philosophical and literary analysis gives the understanding of a text as a phenomenon representing many different voices that reflect personal relations or various subjective positions. According to this, in a text, the relations occur through the location of particular authors in their spatial and temporal context, so they construe the meanings together in the inter-connection with each other. Similarly, the interaction between personalities or subjects in (Volosinov 1973) is qualified as a basic factor that contributes to understanding of language phenomena. Therefore, any utterance is a part of a continuing cognitive speech interaction. Within the framework of the modern discourse-cognitive paradigm, the concept of intersubjectivity helps to explain grammatical phenomena in terms of texts' cognitive and communicative parameters (Latysheva, Sivtseva, \& Fetisova 2017).

Thus, this research makes a hypothesis that the intersubjective approach to the pretranslation analysis of the architectural criticism will neutralize the opposition of objectivism and subjectivism. Consequently, this approach will contribute to the development of an optimal translation strategy in making scientifically grounded translation decisions.

\section{SOURCE TEXT ANALYSIS}

At the first stage of analysis, we applied intertextual approach to identify general characteristics of the source text that are essential for knowledge generation of the field. Belonging to the field of architectural criticism, the text employs complex semiotic structures that involve space arrangements and environment in their connections with individuals and social groups. The text represents material world meant for life, and it transfers messages by means of cultural codes belonging to the world of ideas and values. Thus, it refers not only to engineering and technical studies, but also to sociological, philosophical, cultural, and semiotic research generating knowledge of several domains.

The first feature entails the second characteristic of the source text typical of architectural criticism that is pragmatically complicated, as it performs the tasks of orientation, structural identification and classification, historical and cultural recognition. It is also semantically ambiguous because it combines signs with the reference both to material objects studied by 
hard sciences like geometry or physics, and to figurative and symbolic entities found in arts and humanities. For example, the descriptions of architectural forms can combine technical characteristics (shapes, assemblies and details, materials and technology) and figurative expressions based on associations, metaphors, comparison and symbols.

The third essential feature of the source text is its historical perspective that results from a specific character of architecture which objects reflect historical and cultural context of civilization. This means that the symbolism of traditional architectural forms and its modern interpretations may refer to ideas and values associated with specific historical and cultural events. Therefore, architectural objects become landmarks for interpretations helping to 'read' the skyline of a city.

Architectural signs and symbols denote the utilitarian functions of constructions and connote their symbolic meaning. They are inseparable being a context for interpretation for each other; thus, both meanings are essential for translation. This makes pre-translation analysis within the traditional framework problematic. On the one hand, according to objectivist approach, the analysis is based on the idea of knowledge structures represented in scientific texts.

As a scientific field, architecture employs notions to represent its knowledge about the reality. On the other hand, as an art form related to subjectivist approach, it generates symbols to convey messages and influence emotions. Linguistic analysis puts language units that performs these tasks into different categories. It associates notions with terms and symbols with epithets, metaphors and similar literary techniques. Analytical approach to pre-translation analysis also separates them, as methods of their translation differ.

According to all mentioned above, the pre-translation analysis of the source text revealed two translatological poles influencing further translation decisions. The first pole attracts translators to the sphere of 'hard science', where such parameters as accuracy, objectivity, visibility, materiality, logical structure, lack of emotional colouring, explicit meanings, and unambiguity dominate (Krein-Kühle, 2011). In this case, translators develop a strategy for dealing with terminology that employs the objectivist approach, though the choice of translation methods transferring industry-based terms may depend on individual preferences of translators, as shown in (Timofeeva \& Potapova 2019). Depending on the cognitive and discursive parameters of terminological units, they apply either domestication resulting in semantic and functional techniques of translation or foreignization leading to form-dependent methods of translation (Latysheva 2019).

The second pole, on the contrary, activates the sphere of 'soft science', where translators analyse metaphorical and emotionally coloured vocabulary, implicit and evaluative notions, ambiguity of personal meanings and axiological modality (Boase-Beier, 2014). Under these circumstances, source text nominations obtain the status of artistic techniques, such as metaphors, epithets, oxymoron, comparison, etc. Consequently, translators' decisions are made within the framework of subjectivist approach in order to reveal and transfer the author's individuality. As a result, source text nominations fall into the categories presented in Table 1.

However, the traditional approach opposing objectivist and subjectivist methods discloses a number of composite nominations of the source text that do not belong to either of the categories, as they arise between the two poles with hybrid features that complicate their categorisation. The example in Table 2 illustrates the case. 
Table 1 Translatological poles of the source text

\begin{tabular}{|l|l|}
\hline Hard science pole (terminology) & Soft science pole (artistic techniques) \\
\hline urban planning & historic tragedy \\
settlements & ensuing tyranny of compulsive commuting \\
suburbs & civilizing and emotional qualities (of buildings) \\
structures & insatiable drive for autonomy \\
prefabricated tower blocks & tabula rasa approach \\
mass housing & hodgepodge appearance \\
business park & mistrust of modernism \\
\hline
\end{tabular}

Table 2 Hybrid source text nomination(s)

\begin{tabular}{|c|c|c|c|}
\hline ST nomination(s) & Meanings and functions & $\begin{array}{l}\text { Variants of translation } \\
\text { into Russian, strategies } \\
\text { and translation techniques }\end{array}$ & $\begin{array}{l}\text { Opposition } \\
\text { of objectivist } \\
\text { and } \\
\text { subjectivist } \\
\text { methods }\end{array}$ \\
\hline \multirow[t]{2}{*}{ Skin and skeleton } & $\begin{array}{l}\text { These nominations are } \\
\text { terms; the author develops a } \\
\text { system of notions viewing } \\
\text { architectural objects in the } \\
\text { context of organisms' } \\
\text { existence and sustainability }\end{array}$ & $\begin{array}{l}\text { внешняя облицовка и } \\
\text { конструкции } \\
\text { (vneshnyaya oblicovka } \\
\text { i konstrukcii); } \\
\text { domestication; meaning- } \\
\text { based translation } \\
\text { conveying knowledge } \\
\text { structures }\end{array}$ & 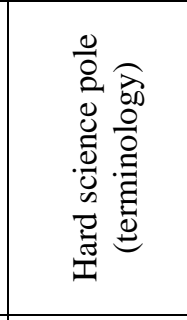 \\
\hline & $\begin{array}{l}\text { This nomination is a } \\
\text { metaphor; the author makes } \\
\text { a comparison relating } \\
\text { building envelopes and } \\
\text { structures to vertebrates } \\
\text { (living organisms with skin } \\
\text { and skeleton) in order to } \\
\text { create a vivid image }\end{array}$ & $\begin{array}{l}\text { кожа и скелет } \\
\text { (kozha i skelet); } \\
\text { foreignization; form- } \\
\text { based translation } \\
\text { conveying the author's } \\
\text { individuality }\end{array}$ & 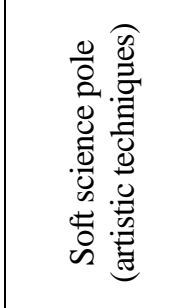 \\
\hline
\end{tabular}

With the traditional approach opposing objectivist and subjectivist methods and results of pre-translation analysis, it is problematic to differentiate between the two translatological poles. Accordingly, it is difficult to identify the appropriate translation strategy resulting in different translation techniques. Therefore, it is necessary to take an alternative approach.

\section{INTERSUBJECTIVE APPROACH AND TRANSLATION STRATEGY}

The peculiar features of architectural criticism discussed above make the process of source text understanding simultaneously related to both translatological poles. Under these conditions, the translator should synchronously act as a knower, a researcher, and an author synthesising scientific, aesthetic, and value paradigms that represent architectural field. 
In accordance with this, at the first stage of pre-translation analysis based on intersubjective approach, we rejected the traditional division of terminology and expressive means of language in the source text and introduced one common category for all the general, specific, neutral, and connotative expressions related to architectural field qualified as architectural nominations.

After that, using the concepts of intersubjectivity and intertextuality, we assumed that the translator creates frames and knowledge structures. Doing so, he focuses the efforts not on a separate term, metaphor or any other meaningful unit, but on the cross-linkage between the architectural nominations of the source text and the dynamic intertextual space leading to the macro context of architectural field. To establish these links, the translator should design the strategy that is in accordance with the matrix of scientific knowledge having been instituted by the time of translation to make progress in the further development of architectural criticism. Thus, the predomination factors that influence the trajectory of interpretation and determine the translation strategy are discursive and cognitive parameters of architectural nominations.

In the framework of intersubjective approach, pre-translation analysis of architectural criticism obtains a supplementary determinant in discourse analysis expressed through varied discursive roles or different types of subjects that interact with each other and reveal internal dialogues within the boundaries of institutions and unlimited creation of individuality. The meanings arise from communication between different traditions, alternative subtexts, and various 'voices' of architecture or discursive roles and practices.

Studies confirm that different types of discursive practices come into operation within a time span, as people take various roles and behave according to culturally determined expectations (Karasik \& Gillespie, 2014). Institutional discourse organizes society making people fulfill their functions or imposing specific behaviour patterns on them. There are agents who embody the institution, and clients who address them. Agents are entitled to lead the discourse, to give expert opinions and recommendations, to express explicit evaluation, etc. (ib.).

In this perspective, institutional discourse is associated with power that institutions need to maintain themselves and to perpetuate their influence. For this purpose, they are obliged to maintain institutional values, meanings and positions (Thompson, 2009). For a translator, this means a high level of conventionality and interpretation of architectural nominations as if they were term or notions. The translation strategy, in this case, is to convey the consensus of authorities by creating terminology in the target text, as shown in example 1 :

(1)

Original sentence: The nickname is the most definitive and devastating criticism that a building can receive because it does not err. It is a revenge of language in general, and of words in particular. The nickname is the correct name for a kitsch object.

Translated into Russian: Прозвище - самая определенная и разрушительная критика, которую может получить здание, потому что оно безошибочно. Это месть языку вообще и словам в частности. Прозвище показывает действительно подходящее название для китч-объекта.

In this passage, the author takes the role of an agent in institutional discourse, as he establishes institutional values by expressing expert's opinion, giving recommendations and creating notions. His discursive practice articulates his authority. Under the influence of this discursive parameters, the underlined architectural nomination conveys the conceptual part of its meaning and loses its expressive content. As a result, by means of foreignization strategy 
combined with the method of word linking, the nomination becomes a unit of terminological system in the target text (kitch-ob"ekt).

Institutional discourse is opposed to personal discourse. Having self-reflective properties, expressing sentiments and giving individual opinions, personal discourse employs pluralism as a leading discursive practice. This means that the translator does not have any interpretation constraints, so the level of conventionality can decrease. As a result, there is a variability in discursive roles. They appear in interactions with institutional discourse, for example, members of oppressed groups, subordinate individuals. As a result, architectural nominations obtain an alternative function. They do not work as notions but convey implicit negative assessments in order to lessen the power of institutional authorities, as shown in example 2:

(2)

Original sentence: These may be the first concrete demonstrations of a form of modernity that is not alienating, kitsch or aggressive but serene and urbane.

Translated into Russian: Выше перечисленные объекты лишь первые конкретные примеры формы современности, которую не нужно сторониться, ведь она не безвкусная и агрессивная, а спокойная и изысканная.

In this context, the similar architectural nomination is translated differently as the author takes a different discursive role. Using the modal verb of possibility, the negative form of the verb and the construction of concession, he stops being authoritative and employs the connotative meaning of architectural nomination. In this case, the translator's aim is to convey the negativity of given estimation. Therefore, the target text displays domestication strategy with the meaning-based translation method resulting in the use of the Russian epithet bezvkusnaya which means tasteless, inellegant.

\section{CONCLUSION}

Intersubjective approach to pre-translation analysis of architectural criticism gives an opportunity to expand the possibilities of discourse-cognitive justification when choosing strategies and methods of translation. The developed approach makes it possible to neutralize the contradictions between the objectivism and subjectivism in pre-translation analysis of architectural criticism, providing the tool for understanding that depends on the roles and nature of interaction of discursive subjects. Further application of this approach will provide a more detailed study of the varieties of discursive roles and intersubjective relations, as well as the identification of the relationship between the types of knowledge and translatological characteristics of the source text. Matching the parameters listed above with discursive practices, a description of relevant translatological parameters of architectural nominations will justify translation decisions simultaneously increasing the level of conventionality within institutional discourse and the specifics of personal meanings of the source text author within personal discourse.

\section{REFERENCES}

Alekseeva, I. S. 2008. Text and Translation. Theoretical issues. Mezhdunarodnye otnoshenija. Alekseeva, L. M. 2010. "Teaching Methods for Written Translation of Specific Text." Ayupova, Roza. 2014. "Pretranslation Text Analysis as a Part of Translation Process." Procedia, Social and Behavioral Sciences 136: 213-16. 
Bakhtin, M. M. 2010. The Dialogic Imagination: Four Essays. University of Texas Press.

Ballard, W. L., and M. A. K. 1980. "Halliday, Language as Social Semiotic: The Social Interpretation of Language and Meaning."

Boase-Beier, Jean. 2014. Stylistic Approaches to Translation. London, England: Routledge.

Brandes, M.P., \& Provotorov, V.I. 2011. Translation Analysis of Text.

Gennaro, F. 2011. "Heidegger, Translation, and the Task of Thinking: Essays in Honor of Parvis Emad."

Karasik, V. I., \& Gillespie, D. 2014. "Discourse personality types.” Procedia - Social and Behavioral Sciences 154: 23-29.

Kemppanen, H., Jänis, M., \& Belikova, A. 2012. Domestication and Foreignization

in Translation Studies. Frank \& Timme GmbH.

Komissarov, Vilen. 2018. "Norms in Translation." In Translation as Social Action, 6375. Routledge.

Krein-Kühle, Monika. 2011. "Register Shifts in Scientific and Technical Translation: A Corpus-in-Context Study." The Translator 17 (2): 391-413.

Latyshev, L. 2016. Translation Technique. Izdatel'stvo Jurajt.

Latysheva, S. V. 2019. "Oil and Gas Industry Lexis Translation: Discourse-Cognitive Approach (Notions versus Terms).” IOP Conference Series. Materials Science and Engineering 483: 012046.

Latysheva, S., N. Sivtseva, and S. Fetisova. 2017. "Indirect Speech Utterance: Intersubjective Approach." In Proceedings of the 7th International Scientific and Practical Conference "Current Issues of Linguistics and Didactics: The Interdisciplinary Approach in Humanities" (CILDIAH 2017). Paris, France: Atlantis Press.

Latysheva, S. V., and N. V. Shchurik. 2015. "Mind-Mapping as a Methodology for Training Written Translation of Specialized Texts: From Analysis to Synthesis."

Nord, C. 1991. "Text Analysis in Translation: Theory, Methodology and Didactic Application of a Model for Translation-Oriented Text Analysis."

Paiva, Claudia Gomes. 1969. "FAIRCLOUGH, N. Analysing Discourse: Textual Analysis for Social Research. Londres: Routledge, 2003.” Discursos Contemporâneos Em Estudo 1 (1): 233-40.

Qassem, M., and V. Gurindapalli. 2019. “Culture-Based Text Analysis in Translation: A Vision for Comprehension, Linguistik Online."

Raman, Pattabi, and Richard Coyne. 2000. "The Production of Architectural Criticism." Architectural Theory Review 5 (1): 83-102.

Robinson, Professor Douglas. 2012. Becoming a Translator: An Introduction to the Theory and Practice of Translation. 3rd ed. Routledge.

Seresová, K., and D. Breveníková. 2019. “The Role of Text Analysis in Translation.” In .

Timofeeva, Lilia, and Tamara Potapova. 2019. "Translation Peculiarities in Oil and Gas Industry." Journal of Teaching English for Specific and Academic Purposes, 573.

Thompson, M. A. 2009. "Language and Power: An Introduction to Institutional Discourse." Edited by Andrea Mayr.

Volosinov, V. N. 1973. Marxism and the Philosophy of Language: Studies in Language. San Diego, CA: Academic Press.

Yang, Wenfen. 2010. "Brief Study on Domestication and Foreignization in Translation." Journal of Language Teaching and Research 1 (1).

Zlateva, Palma. 2000. "Text Analysis as a Tool in Translation Training: Why, How and to What Extent? A Response to Anna Trosborg." Current Issues In Language and Society 7 (3): 261-66. 